\title{
HETEROTROPHIC EUGLENOIDS FROM TROPICAL NORTHERN THAILAND
}

\author{
Kritsana Duanguan, Yuwadee Peerapornpisal \& KonRad Wolowski ${ }^{1}$
}

\begin{abstract}
Among 45 recorded heterotrophic (colorless) taxa of euglenoids, representatives of the genera Petalomonas F. Stein (12 taxa) and Peranema Dujard. (10 taxa) were abundant and showed high diversity. Less frequently identified were Anisonema Dujard. (3), Astasia Dujard. (1), Dinema Perty (2), Entosiphon F. Stein (1), Heteronema Dujard. (4), Menoidium Perty (2), Notosolenus A. Stokes (6), Ploeotia Dujard. (1), Rhabdomonas Fresen. (1) and Urceolus Mereschk. (2). Thirty of these taxa are reported for the first time from northern Thailand. Short descriptions, biogeographical data and original documentation based on light microscopy of living cells in natural communities are included for each reported taxon.
\end{abstract}

Key words: Asia, heterotrophs, euglenoids, distribution, diversity, taxonomy, Thailand

Kritsana Duangjan, Science and Technology Research Institute, Chiang Mai University, Chiang Mai, 50200, Thailand; e-mail: kritsana.du@gmail.com

Yuwadee Peerapornpisal, Department of Biology, Faculty of Science, Chiang Mai University, Chiang Mai, 50200, Thailand; e-mail: Yuwadee.p@cmu.ac.th

Konrad Wołowski, Department of Phycology, W. Szafer Institute of Botany, Polish Academy of Science, Lubicz 46, 31-512, Kraków, Poland; e-mail: k.wolowski@botany.pl

\section{INTRODUCTION}

The first data on colorless euglenoids are associated with the eminent algae researcher Christian Gottfried Ehrenberg (1795-1876). According to Vetrova (1980), Ehrenberg gathered rich samples of water while traveling through the Altai, Urals and western Siberia in 1829. The collection work resulted in a published list of microorganisms, containing a number of euglenoids including heterotrophic ones. He developed the basis for euglenoid classification and described Distigma and other euglenoids (Ehrenberg 1831). The French researcher Félix Dujardin (1801-1860) also contributed significant data, describing Astasia, Peranema, Heteronema, Anisonema and Ploeotia (Dujardin 1841). Another researcher of heterotrophic euglenoids was Friedrich Stein (1818-1885), zoology professor at the University of Prague. Stein (1878) was responsible for describing representatives of the genera Sphenomonas, Petalomonas, Scytomonas, Tropidocyphus

\footnotetext{
1 Corresponding author
}

and Entosiphon. Other renowned phycologists described several genera: Skuja described Gyropaigne and Dylakosoma (Skuja 1939, 1964); Christen identified Atractomonas, Parmidium and Calycimonas (Christen 1959, 1962); Pringsheim (1963) is the author of Rhabdospira; and Mereschkowsky (1879) studied Urceolus. Very common taxa of the genus Menoidium were described by Perty (1852), and those of the similar genus Rhabdomonas by Fresenius (1858). Various heterotrophic groups of euglenoids described over the years, such as Euglenopsis (Klebs 1892), Khawkinea (Jahn \& McKibben 1937), Dinematomonas (Silva 1960) and Notosolenus A. Stokes (1884), are important to the phylogeny of euglenoids.

A review of the literature on heterotrophic euglenoids makes it clear that most of their data originate from Europe. These descriptions are linked mostly with temperate-zone euglenoids. Compilations serving as identification keys for algae contain some information about heterotrophic euglenoids from the territory of the present-day 
Czech Republic (Hansgirg 1886) and the waters of Germany (Lemmermann 1913). Research on heterotrophic euglenoids by Pringsheim (1963) and Leedale $(1967,1985)$ is of great importance. Huber-Pestalozzi (1955) and Starmach (1983) compiled species of euglenoids from almost the entire planet.

There are only a few monographs containing information about colorless euglenoids from different European regions. Popova and Safonova (1976) published an exhaustive work on the colorless euglenoids of the former Soviet Union. Asaul (1975) and Vetrova (1980, 2004) published splendid works on the colorless euglenoids of Ukrainian continental waters, which provide very interesting information about the ecology of this group. Some data on colorless taxa from Austria were given by Kusel-Fetzmann (2002). Poniewozik (2005, 2012, 2014) reported colorless taxa from eastern Poland, and Wołowski (1991, 1998), Cabala (2003) and Piątek (2007) reported colorless taxa from the Kraków-Częstochowa Upland. Wołowski also studied heterotrophic euglenoids of the United Kingdom (Wołowski 2011). The taxonomy and morphology of various heterotrophic euglenoid taxa were studied by Angeler (1999a, b, 2000) and Angeler et al. (2002). For tropical and subtopical areas of Australia there are data on freshwater heterotrophic euglenoids (Playfair 1921; Larsen \& Patterson 1990) and marine colorless euglenoids (Lee et al. 1999, 2000, 2003, 2005; Lee 2002). Free-living heterotrophic euglenoids from freshwater sites in Australia were described and illustrated by Schroeckh et al. (2003) and Lee et al. (2005). Taxonomic information on heterotrophic euglenoids of North America is still far from complete; there are no major taxonomic studies with proper documentation. Numerous data are given by Jahn and Jahn (1949), Jahn and McKibben (1937) and Shawhan and Jahn (1947). A few heterotrophic euglenoids were recorded by Whitford $(1956,1958,1979)$ in North Carolina. Wołowski and Walne (1997) reported heterotrophic euglenoids from the southeastern United States. The situation is similar in South America, where most data came from Brazil (Cunha 1913; Bicudo \& Bicudo 1987; Rosa et al. 1987; Menezes 1993;
Alves-da-Silva \& Friedrich 2009). These results are summarized in the Catalogue of plants and fungi of Brazil (Alves-da-Silva \& Menezes 2010). Some taxa were reported from Argentina by Conforti (1979, 1980, 1981a, b, 1986) and Tell (1985). From Africa very few taxa have been reported: Astasia torta E. G. Pringsh., Gyropaigne lefrevrei Bourr. \& Georges (Alfinito 2011), Astasia inflata Dujard., Menoidium gracile Playfair and Scytomonas pusilla F. Stein (Reinhold 1937).

Most Asian studies on heterotrophic euglenoids come from China. Shi (1999) gave many descriptions in Flora alarum sinicarum aquae dulcis. Some information from Southeast Asia can be found in work by Lee (2002) and Yamagishi (1992, 2010). Important data from subtropical and tropical regions of Thailand were collected during studies of protozoans by Charubhun and Charubhun (2000), Jaisa-ard (2000) and Matchacheep and Dumrongrojwattana (2010). Recently Chaimongkhon (2016) reported 14 taxa from 6 genera of colorless euglenoids in some waterbodies of Thailand: Anisonema (4 taxa), Heteronema (1), Menoidium (1), Notosolenus (2), Peranema (4) and Petalomonas (2).

The present study documents the diversity of colorless euglenoids occurring in freshwaters of northern Thailand.

\section{MATERIALS AND METHODS}

Samples were taken from various types of water bodies every month over a single year from April 2009 to March 2010 in Chiang Mai, Chiang Rai, Lamphun, Lampang and Phayao provinces (Table 1).

Samples were collected with a plankton net (10 $\mu \mathrm{m}$ pore size) and a slime aspirator into plastic flasks ( $c a 100 \mathrm{ml}$ ) and divided into two parts. One part was preserved with $2 \%$ formaldehyde and the other part was transported as live material. Both parts were studied under a light microscope (Nikon, ECLIPSE 600) in the laboratory. All descriptions are based on phenotype observations of living specimens. More detailed descriptions of the examined habitats can be found in earlier papers by Duangjan and Wołowski (2013) and Wołowski et al. (2015).

The physicochemical properties of water, including $\mathrm{pH}$, temperature, conductivity and nutrient content (nitrate nitrogen, ammonium nitrogen, orthophosphate) 
Table 1. Location and description of sampling sites.

\begin{tabular}{|c|c|c|c|}
\hline Provinces & Site code & Geographical coordinates & Site characteristics \\
\hline \multirow[t]{4}{*}{ 1. Chiang Mai } & $\mathrm{AG}$ & $\begin{array}{l}18^{\circ} 47^{\prime} 36.00^{\prime \prime} \mathrm{N} \\
98^{\circ} 57^{\prime} 40.02^{\prime \prime} \mathrm{E}\end{array}$ & $\begin{array}{l}\text { Garden pond at Chiang Mai University, shallow, transparent, } \\
\text { with lotus (plants). }\end{array}$ \\
\hline & $\mathrm{UM}$ & $\begin{array}{l}18^{\circ} 46^{\prime} 55.98^{\prime \prime} \mathrm{N} \\
98^{\circ} 57^{\prime} 5.46^{\prime \prime} \mathrm{E}\end{array}$ & Fish pond at Wat Umong, mostly with catfish. \\
\hline & MJ1 & $\begin{array}{l}18^{\circ} 53^{\prime} 55.80^{\prime \prime} \mathrm{N} \\
99^{\circ} 0^{\prime} 59.94^{\prime \prime} \mathrm{E}\end{array}$ & Fish pond at Maejo University, with Mekong giant catfish. \\
\hline & $\mathrm{KL}$ & $\begin{array}{l}18^{\circ} 19^{\prime} 8.22^{\prime \prime} \mathrm{N} \\
99^{\circ} 28^{\prime} 0.54^{\prime \prime} \mathrm{E}\end{array}$ & Fish pond at Khelang Nakorn School, with Nile tilapia. \\
\hline \multirow[t]{2}{*}{ 2. Lampang } & TJ & $\begin{array}{l}18^{\circ} 18^{\prime} 37.80^{\prime \prime} \mathrm{N} \\
99^{\circ} 29^{\prime} 41.94^{\prime \prime} \mathrm{E}\end{array}$ & $\begin{array}{l}\text { Fish pond at Wat Phra Jao Tanjai, with Nile tilapia, with water } \\
\text { hyacinth. }\end{array}$ \\
\hline & LL & $\begin{array}{l}18^{\circ} 32^{\prime} 44.04^{\prime \prime} \mathrm{N} \\
99^{\circ} 1^{\prime} 57.60^{\prime \prime} \mathrm{E}\end{array}$ & Ditch in front of Lanlao Restaurant. \\
\hline \multirow[t]{2}{*}{ 3. Lamphun } & $\mathrm{BL}$ & $\begin{array}{l}18^{\circ} 36^{\prime} 41.70^{\prime \prime} \mathrm{N} \\
99^{\circ} 2^{\prime} 3.18^{\prime \prime} \mathrm{E}\end{array}$ & Field pond in front of Bualuang Restaurant. \\
\hline & LP1 & $\begin{array}{l}18^{\circ} 38^{\prime} 7.62^{\prime \prime} \mathrm{N} \\
99^{\circ} 3^{\prime} 3.42^{\prime \prime} \mathrm{E}\end{array}$ & Field pond near agriculture areas, on the road side. \\
\hline \multirow[t]{2}{*}{ 4. Chiang Rai } & $\mathrm{CC} 1$ & $\begin{array}{l}19^{\circ} 16^{\prime} 2.46^{\prime \prime} \mathrm{N} \\
99^{\circ} 30^{\prime} 42.60^{\prime \prime} \mathrm{E}\end{array}$ & $\begin{array}{l}\text { Fish pond in the area of Cabbage \& Condom Inn and Restaurant, } \\
\text { with a carp. }\end{array}$ \\
\hline & BY1 & $\begin{array}{l}19^{\circ} 47^{\prime} 7.20^{\prime \prime} \mathrm{N} \\
99^{\circ} 44^{\prime} 40.38^{\prime \prime} \mathrm{E}\end{array}$ & Shallow garden pond at the Pa Ko Dam Tobacco Station. \\
\hline \multirow[t]{2}{*}{ 5. Phayao } & AS & $\begin{array}{l}19^{\circ} 10^{\prime} 17.16^{\prime \prime} \mathrm{N} \\
99^{\circ} 54^{\prime} 4.38^{\prime \prime} \mathrm{E}\end{array}$ & Ditch in front of Kindergarten Phayao School. \\
\hline & PS1 & $\begin{array}{l}19^{\circ} 10^{\prime} 16.80^{\prime \prime} \mathrm{N} \\
99^{\circ} 54^{\prime} 35.82^{\prime \prime} \mathrm{E}\end{array}$ & Fish pond at Phayaopitthayakom School, with fishpens. \\
\hline
\end{tabular}

were analyzed. Water $\mathrm{pH}$ and conductivity were determined with an SMS125 pH/ORP controller. Nutrient concentrations $\left(\mathrm{PO}_{4}{ }^{3-}, \mathrm{NO}_{3}{ }^{-}, \mathrm{NH}_{4}{ }^{+}\right)$were measured in the laboratory: nitrate nitrogen analysis by the cadmium reduction method, ammonium nitrogen analysis by the Nesslerization method, and orthophosphate by the ascorbic acid method (Eaton et al. 2005). Nomenclature follows Pringsheim (1942), Huber-Pestalozzi (1955), Kudo (1977), Starmach (1983), Wołowski $(1998,2011)$ and Leedale (2000). We checked all data against the Algaebase (Guiry \& Guiry 2016) and the International Code of Zoological Nomenclature (ICZN).

\section{RESULTS AND DISCUSSION}

Colorless euglenoids were found in highly polluted waterbodies. Water $\mathrm{pH}$ ranged from 5.21 to 9.40 , conductivity from 93 to $1104 \mu \mathrm{S} / \mathrm{cm}$, and nutrient levels from $<0.01$ to $2.37 \mathrm{mg} / \mathrm{L}$ for nitrate nitrogen, $<0.01$ to $4.45 \mathrm{mg} / \mathrm{L}$ for ammonium nitrogen, and $<0.01$ to $1.07 \mathrm{mg} / \mathrm{L}$ for orthophosphates (Table 2). Half of the studied sites were fish ponds (6), followed by field ponds (2), ditches
(2) and garden ponds (2). They all showed very similar levels of phosphorus, nitrates and ammonium (Table 2). We found very high conductivity of water in two ponds: a ditch in front of the kindergarten in Phayao, and a fish pond in Lampang. Among the 12 investigated sites, we recorded high diversity (28 taxa) in a fish pond (KL) with Nile tilapia in Lampang, and 18 taxa in a catfish pond (UM) in Chiang Mai. No more than 10 taxa occurred in the other ponds. The fewest taxa (3) were noted in a fish pond with Mekong giant catfish at Maejo University in Chiang Mai Province and in a field pond in front of the Bualuang Restaurant in Lamphun (LL). Twenty-five taxa occurred only once in one type of site (Table 3). In various types of sites we found Entosiphon sulcatus (Dujard.) F. Stein, Heteronema leptosomum Skuja, Peranema cryptocercum (Skuja) T. G. Popova, P. cuneatum Playfair and Petalomonas minutula Christen.

Thirty of the 45 taxa colorless euglenoids recorded in this study are reported here as new for the heterotrophic euglenoid flora of Thailand (see 


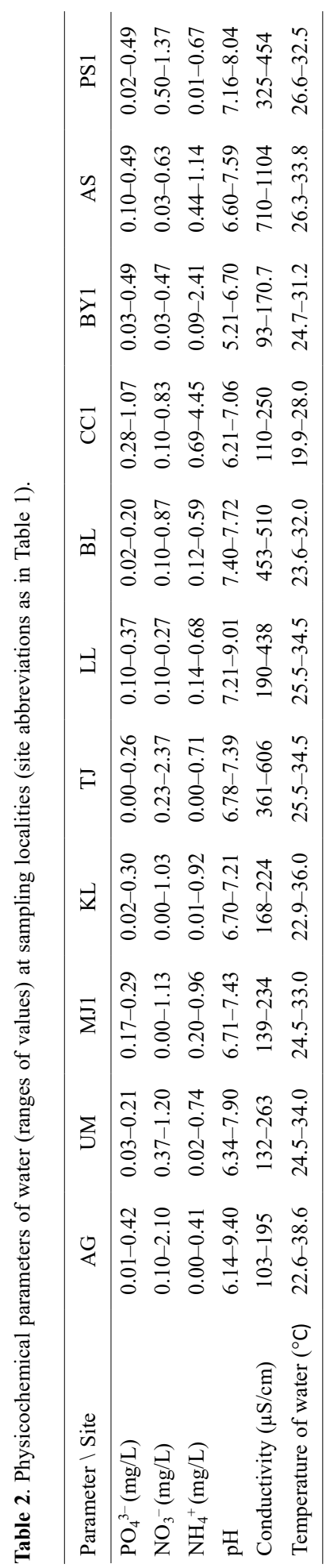

Table 3, Fig. 70). All descriptions of the newly recorded colorless euglenoids given below are based on observations of morphological characters.

Astasia Dujard.

Astasia dangeardii Lemmerm.

Figs $1 \& 37$

Cells with pronounced euglenoid movement, 42.8-62.5 $\mu \mathrm{m}$ long, 7.1-10.0 $\mu \mathrm{m}$ wide, longitudinally club- or spindle-shaped; anterior end oblique; posterior end gradually narrow; paramylon bodies quite large, round or rod-shaped; flagellum slightly shorter than body.

SITE: Lampang - fish pond (KL).

GENERAL OCCURRENCE: common, stagnant water bodies, swamps, fish ponds, polysaprobic (Vetrova 1980); reported from Asia: China (Shi 1999), India (Gupta 2012); Europe: Switzerland, Ukraine, Russia (Starmach 1983), British Isles (Wołowski 2011).

\section{Dinema Perty}

Dinema dimorphum (Skuja) Schroeckh, W. J. Lee \& D. J. Patt.

Figs $2 \& 38$ Anisonema dimorphum Skuja

Cells 42.2-50.0 $\mu \mathrm{m}$ long, 14.5-17.5 $\mu \mathrm{m}$ wide, flexible, broadly ovoid or obovoid, usually elliptical, flat, inversely heart-shaped; with S-shaped groove; pellicle fairly thick, densely spiral-striated, striations finely granulate; posterior flagellum twice the length of cell.

Note. The ingestion organelle was not visible, and our specimens were slightly narrower than those described by Skuja (1934).

Site: Chiang Rai - garden pond (BY1).

GENERAL OCCURRENCE: not common, lakes, littoral; reported from Asia: India (Gupta 2012) Australia (Schroeckh et al. 2003); Europe: Latvia and Sweden (Starmach 1983).

Dinema platysomum (Skuja) W. J. Lee \& D. J. Patt.

Figs 3 \& 39 Anisonema platysomum Skuja

Cells 25.0-31.2 $\mu \mathrm{m}$ long, 12.5-16.2 $\mu \mathrm{m}$ wide, 
Table 3. Occurrence of heterotrophic euglenoids $\left({ }^{*}-\right.$ new for Thailand; site abbreviations as in Table 1).

\begin{tabular}{|c|c|c|c|c|c|c|c|c|c|c|c|}
\hline Taxon / Site & AG & $\mathrm{UM}$ & MJ1 & KL & TJ & LL & $\mathrm{BL}$ & $\mathrm{CC} 1$ & BY1 & AS & PS1 \\
\hline Anisonema acinus Dujard. & - & - & - & - & - & - & - & + & - & - & - \\
\hline A. ovale G. A. Klebs & - & + & - & + & - & - & - & + & + & - & + \\
\hline A. prosgeobium Skuja & + & - & - & + & - & - & - & + & - & + & - \\
\hline${ }^{*}$ Astasia dangeardii Lemmerm. & - & - & - & + & - & - & - & - & - & - & - \\
\hline $\begin{array}{l}\text { * Dinema dimorphum (Skuja) Schroeckh, W. J. Lee } \\
\text { \& D. J. Patt. }\end{array}$ & - & - & - & - & - & - & - & - & + & - & - \\
\hline${ }^{*}$ D. platysomum W. J. Lee \& D. J. Pett. & - & + & - & & - & - & - & - & - & + & - \\
\hline${ }^{*}$ Entosiphon sulcatum (Dujard.). F. Stein & + & + & - & + & + & + & + & + & + & + & + \\
\hline Heteronema acus (Ehrenb.) F. Stein & + & - & - & - & + & + & - & - & + & - & - \\
\hline${ }^{*}$ H. hexagonum var. elegans Playfair & - & - & - & - & + & - & - & - & - & - & - \\
\hline H. leptosomum Skuja & - & + & - & + & + & + & - & - & - & + & + \\
\hline${ }^{*}$ H. polymorphum Deflandre & - & - & - & + & - & - & - & - & - & - & - \\
\hline${ }^{*}$ Menoidium pellucidum Perty & - & + & - & + & - & - & - & - & - & - & - \\
\hline${ }^{*}$ M. tortuosum (Stokes) Lemmerm. & - & - & - & + & - & - & - & - & - & - & - \\
\hline Notosolenus obliquus Skuja & - & + & - & - & - & - & - & - & - & - & - \\
\hline${ }^{*} N$. pentagonus Playfair & + & - & - & - & - & + & - & - & - & - & - \\
\hline $\begin{array}{l}{ }^{*} \text { N. mediocanellata var. dissomatus (A. Stokes) } \\
\text { Duangian \& Wolowski }\end{array}$ & - & - & - & - & - & - & + & - & - & - & - \\
\hline${ }^{*} N$. similis Skuja & - & - & - & - & - & - & - & + & - & - & - \\
\hline${ }^{*}$ N. steinii Schroeckh, W. J. Lee \& D. J. Patt. & + & + & - & - & - & - & - & - & - & - & - \\
\hline${ }^{*}$ N. stenoschismus Skuja & - & + & - & + & - & - & - & - & + & + & - \\
\hline Peranema cryptocercum T. G. Popova & - & + & + & + & + & + & - & - & - & - & + \\
\hline${ }^{*}$ P. cuneatum Playfair & - & + & - & - & + & + & + & - & - & - & + \\
\hline P. deflexum Skuja & - & - & - & + & - & - & & - & - & - & - \\
\hline${ }^{*}$ P. inflexum Skuja & - & - & - & - & - & - & + & - & - & - & - \\
\hline P. limax Christen & + & - & - & - & - & - & - & - & - & - & - \\
\hline${ }^{*}$ P. kupfferi Skuja & - & + & - & - & - & - & - & - & - & - & - \\
\hline P. nigrum Christen & - & + & - & - & + & - & - & - & - & - & - \\
\hline${ }^{*}$ P. pleururum Skuja & + & + & - & - & - & + & - & - & - & - & - \\
\hline P. sacculus Christen & + & + & - & + & + & + & - & + & - & + & - \\
\hline P. trichophorum (Ehrenb.) F. Stein & + & + & - & + & + & + & + & + & + & + & + \\
\hline${ }^{*}$ Petalomonas abscissa (Dujard.) F. Stein & - & - & - & + & - & - & - & - & - & - & - \\
\hline${ }^{*}$ P. angusta Lemmerm. & - & - & - & + & - & - & - & - & - & - & - \\
\hline${ }^{*}$ P. angusta var. pusilla (Klebs) Lemmerm. & - & - & - & + & - & - & - & - & - & - & - \\
\hline${ }^{*}$ P. asymmetrica Schawhan \& Jahn & - & - & - & + & - & - & - & - & - & - & - \\
\hline${ }^{*}$ P. dubosqui Hollande & - & - & - & + & - & - & - & - & - & - & - \\
\hline${ }^{*}$ P. inflexa G. A. Klebs & - & - & - & - & - & + & - & - & - & - & - \\
\hline${ }^{*}$ P. irregularis Skuja & + & - & - & - & - & - & - & - & - & - & - \\
\hline P. mediocanellata F. Stein & - & + & - & + & - & + & - & - & + & - & - \\
\hline P. minutula Christen & - & + & - & + & + & + & - & + & + & + & - \\
\hline${ }^{*}$ P. mira var. bicarinata Skuja & - & - & - & + & - & - & - & - & + & - & - \\
\hline${ }^{*}$ P. splendens Hollande & - & + & - & - & - & - & - & - & - & - & - \\
\hline${ }^{*}$ P. variabilis Christen & + & - & + & - & - & - & - & - & - & - & - \\
\hline${ }^{*}$ Ploeotia obligua Schroeckh, W. J. Lee \& D. J. Patt. & - & - & - & + & - & - & - & + & - & - & - \\
\hline${ }^{*}$ Rhabdomonas incurva Fresen. & - & - & + & + & - & + & - & - & - & - & - \\
\hline${ }^{*}$ Urceolus pascheri Skvortzov & - & - & - & + & - & - & - & - & - & - & - \\
\hline U. subulosus A. Stokes & - & - & - & + & - & - & - & - & - & - & - \\
\hline
\end{tabular}


slightly flexible, ovoid, flat; anterior end shortly pointed; posterior end broadly round; with shallow longitudinal groove; posterior flagellum twice the length of cell, anterior flagellum much shorter.

Note. The ingestion organelle was not visible. (AS).

SITES: Chiang Mai - fish pond (UM); Phayao - ditch

GENERAL OCCURRENCE: saltwater and freshwater, ditches; reported from Europe: Latvia; Asia: India (Starmach 1983); Australia (Patterson \& Lee 2000).

\section{Entosiphon F. Stein}

\section{Entosiphon sulcatum (Dujard.) F. Stein}

Figs 4, 5, 40, 41

Cells 21.1-25.0 $\mu \mathrm{m}$ long, 12.5-17.5 $\mu \mathrm{m}$ wide, oval to broadly oval, slightly flattened; depression at anterior end with ingestion siphon; posterior end round; pellicle with 8-12 longitudinal ribs and wide groove; siphon does not reach end of cell; anterior flagellum almost as long as cell, posterior flagellum twice the length of cell.

Sites: Lampang - fish pond (KL); Phayao - fish pond (PS1).

GENERAL OCCURRENCE: common, planktonic in lakes and ponds, surface of sediment; reported from Asia: China (Shi 1999); North America: USA, Tennessee (Wołowski \& Walne 1997), Mexico (Figueroa-Torres et al. 2015); South America: Argentina (Tell 1985), Brazil (Cunha 1913); Australia (Schroeckh et al. 2003, Lee et al. 2005); Europe: Austria Germany, Latvia, Russia (Vetrova 1980).

\section{Heteronema Dujard.}

Heteronema hexagonum var. elegans Playfair Figs $6 \& 42$

Cells with euglenoid movement, 30.0-38.5 $\mu \mathrm{m}$ long, 12.5-17.1 $\mu \mathrm{m}$ wide, not flattened, spindleshaped; 1-2 spiral groove(s) on surface; narrow groove runs on ventral side; anterior flagellum longer than cell, posterior flagellum shorter than cell.

SITE: Lampang - fish pond (TJ).
GENERAL OCCURRENCE: stagnant waterbodies; reported from Australia and Europe: Russia, Switzerland (Starmach 1983).

Heteronema polymorphum Deflandre

Figs $7,8,43,44$

Cells with euglenoid movement, 35.0-55.2 $\mu \mathrm{m}$ long, 15.0-18.7 $\mu \mathrm{m}$ wide, during swimming longitudinally cylindrical, narrow toward both ends; anterior flagellum slightly shorter than cell, posterior flagellum a third the length of anterior flagellum.

Note. Our specimen was smaller than those described by Deflandre (1932) but other features were compatible.

SITE: Lampang - fish pond (TJ).

GENERAL OCCURRENCE: not common, stagnant and slightly flowing waters, saprophytic; reported from Asia: China (Shi 1999); South America: Argentina (Tell 1985); Europe: Ukraine, Russia (Starmach 1983).

\section{Menoidium Perty}

Menoidium pellucidum Perty Figs 9-11, 45, 46

Cells 33.4-57.5 $\mu \mathrm{m}$ long, 6.6-10.0 $\mu \mathrm{m}$ wide, elongated, curved, sickle-shaped, flat; narrowly triangular in cross section; anterior end slightly narrow and elongated, often with 1-2 serrated spine(s); posterior end bluntly round; flagellum shorter than cell.

Sites: Chiang Mai - fish pond (UM); Chiang Rai fish pond (BY1); Lampang - fish pond (KL).

GENERAL OCCURRENCE: very common, ditches, ponds; worldwide, reported from Asia: Cambodia (Yamagishi 2010), China (Shi 1999), India (Gupta 2012); South America: Brazil (Cunha 1913; Alvesda-Silva \& Menezes 2010); Australia (Schroeckh et al. 2003); Europe (Wołowski 2011).

Menoidium tortuosum (A. Stokes) Lemmerm. Figs $12 \& 47$

Cells 37.5-55.0(-62.5) $\mu \mathrm{m}$ long, 2.5-7.5 $\mu \mathrm{m}$ wide, narrow S-shaped, twisted; anterior end elongated, blunt; posterior end gradually narrowing; flagellum shorter than cell. 

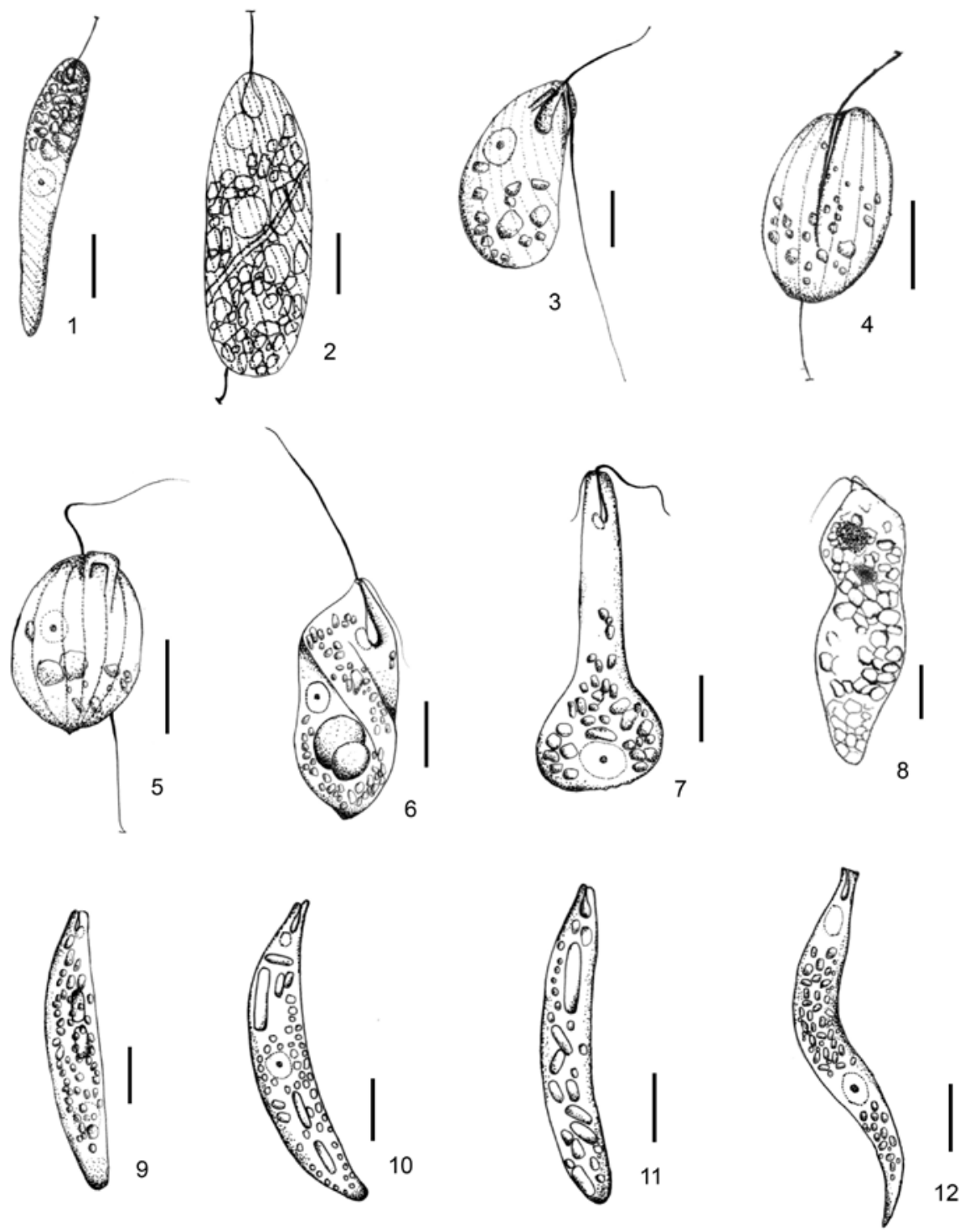

Figs 1-12. 1 - Astasia dangeardii Lemmerm., 2 - Dinema dimorphum (Skuja) Schroeckh, W. J. Lee \& D. J. Patt., 3 - D. platysomum (Skuja) W. J. Lee \& D. J. Patt., 4 \& 5 - Entosiphon sulcatum (Dujard.) F. Stein, 6 - Heteronema hexagonum var. elegans Playfair, $7 \& 8-H$. polymorphum Deflandre, 9-11 - Menoidium pellucidum Perty, 12 - M. tortuosum (A. Stokes) Lemmerm. Scale bars $=10 \mu \mathrm{m}$.

SiTE: Lampang - fish pond (KL).

GENERAL OCCURRENCE: very common, $\alpha$-mezosaprobe; reported from Europe, Asia, North America, Australia (Wołowski 2011) and South America (Alves-da-Silva \& Friedrich 2009; Alves-da-Silva $\&$ Menezes 2010).
Notosolenus A. Stokes

Notosolenus pentagonus Playfair Figs $13 \& 48$

Cells with euglenoid movement, 24.1-30.0 $\mu \mathrm{m}$ long, $16.5-20.0 \mu \mathrm{m}$ wide, $12 \mu \mathrm{m}$ thick, penta lateral in outline, flat; both ends narrow; lateral sides 

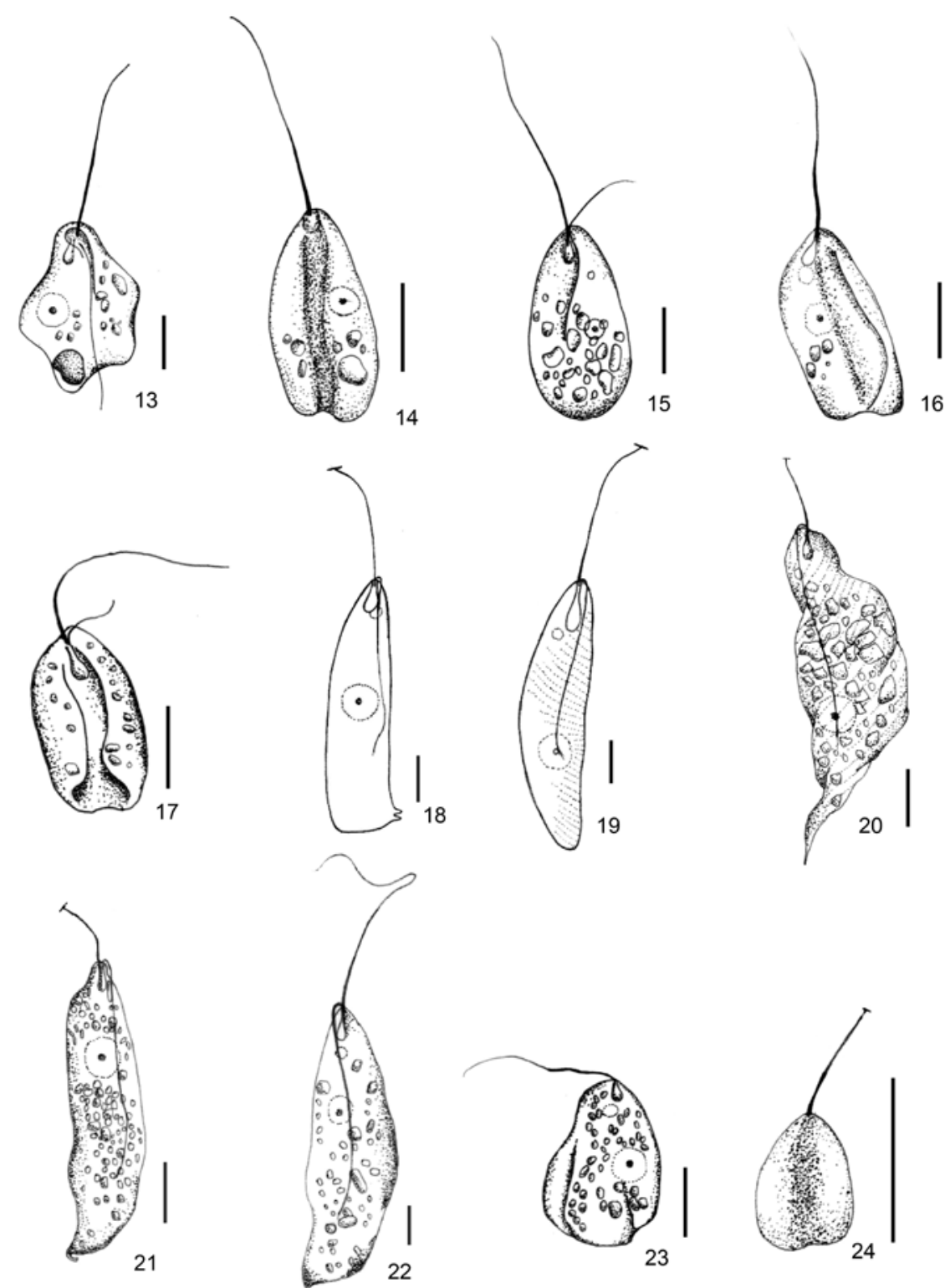

Figs 13-24. 13 - Notosolenus pentagonus Playfair, 14 - N. mediocanellatus var. disomatus (A. Stokes) Duangjan \& Wolowski, 15 - N. similis Skuja, 16 - N. steinii (Klebs) Schroeckh, W. J. Lee \& D. J. Patt., 17 - N. stenoschismus Skuja, 18 - Peranema cuneatum Playfair, 19 - P. inflexum Skuja, 20 - P. kupfferi Skuja, 21 \& 22 - P. pleururum Skuja, 23 - Petalomonas abscissa (Dujard.) F. Stein, $24-P$. angusta var. pusilla (Klebs) Lemmerm.. Scale bars $=10 \mu \mathrm{m}$.

wavy; dorsal side slightly convex, with 2-4 low slats; ventral side flat, concave, with slight grooves; anterior flagellum as long as or slightly longer than cell, posterior flagellum slightly shorter than anterior flagellum.
Site: Lamphun - fish pond (LL).

GENERAL OCCURRENCE: rare, stagnant water bodies, reported from Australia (Playfair 1921; Schroeckh et al. 2003). 


\section{Notosolenus mediocanellatus var. disomatus}

(A. Stokes) Duangian \& Wolowski, comb. nov.

Figs $14 \& 49$

Basionym: Petalomonas disomata A. Stokes, Amer. Monthly Micr. J. 5: 125, figs 7-9. 1884.

Petalomonas mediocanellata F. Stein var. disomata (A. Stokes) Lemmerm., Kryptogamenfl. Mark Brandenburg 3: 551. 1910.

Cells 15.0-24.6 $\mu \mathrm{m}$ long, 7.5-11.5 $\mu \mathrm{m}$ wide, ovoid or pear-shaped, flat; compressed with median longitudinal groove on ventral and dorsal sides; anterior end narrow and truncated; posterior end broadly rounded; anterior flagellum as long as or slightly longer than cell.

Note. The short flagellum was not visible.

Site: Lamphun - field pond (BL).

GENERAL OCCURRENCE: common, stagnant water bodies, in mud; reported from Asia: China (Shi 1999); Europe: Ukraine, Poland, Latvia, Russia (Vetrova 1980), United Kingdom (Wołowski 2011); North America (Starmach 1983); South America: Brazil (Cunha 1913), Argentina (Conforti 1979; Tell 1985).

\section{Notosolenus similis Skuja}

Figs $15 \& 50$

Cells with weak euglenoid movement, 22.5$28.7 \mu \mathrm{m}$ long, $12.5-16.2 \mu \mathrm{m}$ wide, ovoid, flat; anterior end pointed, posterior end broadly or sharply rounded; convex on dorsal side; flat and concave on ventral side; anterior flagellum slightly longer than cell, posterior flagellum much shorter. This species has a longitudinal groove (see Fig. 50).

Note. Schroeckh et al. (2003) made a detailed study of it and compared various morphological characters with those of other taxa.

Site: Chiang Rai - fish pond (CC1).

General ocCurRence: common, ponds, ditches, fresh and marine waters, tropical marine sediments; reported from Australia and South America (Larsen \& Patterson 1990); Europe: Latvia, western Russia, Switzerland (Skuja 1939).

Notosolenus steinii (G. A. Klebs) Schroeckh, W. J. Lee \& D. J. Patt.

Figs $16 \& 51$

= Petalomonas steinii $\mathrm{G}$. A. Klebs
Cells 22.5-26.9 $\mu \mathrm{m}$ long, 12.3-15.0 $\mu \mathrm{m}$ wide, ovoid, almost triangular or oval; anterior end rounded; dorsal face has a longitudinal central ridge, may extend laterally as a wing; flagellum 1-1.5 times longer than cell; posterior flagellum very short (3-6 $\mu \mathrm{m}$ long), lying in narrow ventral groove, sometimes not visible.

Notes. According to Schroeckh et al. (2003) this species was transferred to Notosolenus. They observed two flagella; a second flagella was not visible in our specimens.

SITES: Chiang Mai-fish pond (UM), garden pond (AG).

General ocCUrRence: ditches, ponds, swamps, $\alpha-\beta$-mezosaprobe; reported from Asia: China (Shi 1999), Cambodia (Yamagishi 2010); Australia (Schroeckh et al. 2003); Europe: Latvia, Ukraine, Russia; North America (Vetrova 1980); South America: Brazil (Cunha 1913), Argentina (Conforti 1979; Tell 1985), Brasilia (Alves-daSilva \& Menezes 2010).

Notosolenus stenoschismus Skuja Figs 17 \& 52

Cells with weak euglenoid movement, 15.0$22.2 \mu \mathrm{m}$ long, 7.5-12.2 $\mu \mathrm{m}$ wide, ovoid, slightly flat; anterior end extended, narrow; posterior bluntly round; dorsal side of cell strongly convex; ventral side weakly grooved with narrow, deep groove on right side, connected to throat at anterior part; anterior flagellum almost as long as cell, posterior flagellum three times shorter.

Note. Resembles $N$. similis in shape and size but $N$. similis is distinguished from N. stenoschismus by the presence of a dorsal groove (Schroeckh et al. 2003)

Sites: Chiang Mai - fish pond (UM); Lampang - fish pond (KL); Chiang Rai - garden pond (BY1); Phayao - ditch (AS).

GENERAL OCCURRENCE: not common, dam, ponds; reported from Europe: Latvia; Australia (Schroeckh et al. 2003)

Peranema Dujard.

Peranema cuneatum Playfair Fig. 18

Cells with euglenoid movement, 37-62 $\mu \mathrm{m}$ long, 10-16 $\mu \mathrm{m}$ wide, cylindrical; anterior end slightly 
narrow; posterior end usually with bifurcated spine; canal opening subapical; two unequal emergent flagella, one directed forward, the second to posterior part and usually lying on pellicle.

Sites: Chiang Mai - fish pond (UM); Lampang fish ponds (TJ, KL), Lamphun - fish pond (BL); Phayao - fish pond (PS1).

GenerAL OCCURRENCE: small water bodies, ponds; reported from Asia: China (Shi 1999), India (Gupta 2012); South America: Argentina (Tell 1985); Australia (Playfair 1921).

\section{Peranema inflexum Skuja}

Fig. 19

Cells with euglenoid movement, 31-43 $\mu \mathrm{m}$ long, 8-10 $\mu \mathrm{m}$ wide, spindle-shaped, bent and slightly twisted; anterior end narrow, oblique; posterior end broadly flat; anterior flagellum as long as cell or longer, directed forward, the second directed to posterior part and usually lying on pellicle, sometimes poorly visible, can be overlooked.

Note. Similar to P. cuneatum Playfair and P. pleururum Skuja and P. trichophorum (Ehrenb.) F. Stein; they can be distinguished from $P$. inflexum by their larger size and flatter cell shape. According to Schroeckh et al. (2003) this species was reported from Australia by Playfair (1921) as $P$. trichophorum.

Site: Lamphun - field pond (BL).

General ocCURRENCE: common, forest ditches, worldwide; reported from Asia: China (Shi 1999); Europe: Latvia (Skuja 1931); South America: Argentina (Tell 1985); North America: USA (Smith 2010); Australia (Schroeckh et al. 2003); Tasmania (Lee et al. 2005).

\section{Peranema kupfferi Skuja}

Figs $20 \& 53$

Cells with euglenoid movement, 45-125 $\mu \mathrm{m}$ long, 15.0-37.5 $\mu \mathrm{m}$ wide, spindle-shaped in outline; anterior end narrow, oblique; posterior end narrow, with pointed appendix; paramylon body oval; two flagella, the anterior one nearly as long as cell, directed forward, the second one shorter than cell, directed to posterior, can be overlooked.

Sites: Chiang Mai - fish pond (UM); Lampang fish pond (TJ).
GENERAL OCCURRENCE: not common, forest ditches; reported from Asia: western Siberia; Europe: Latvia, United Kingdom (Wołowski 2011).

Peranema pleururum Skuja Figs 21, 22, 54, 55

Cells with euglenoid movement, 38.8-75.0 $\mu \mathrm{m}$ long, 12.5-25.0 $\mu \mathrm{m}$ wide, wide lancet-shaped or spindle-shaped, slightly flattened, sometimes twisted; anterior end elongated, oblique; posterior end narrow, incised end, with lateral appendix; groove narrow on ventral side; pellicle quite thick, longitudinally striated, striation interrupted; anterior flagellum thick, longer than cell, posterior flagellum thin, lying in groove.

Sites: Chiang Mai - fish pond (UM), garden pond (AG).

GenerAL OCCURRENCE: rare, small rivers, ponds, puddles; reported from Asia: India (Gupta 2012); Europe: Latvia, Ukraine, Russia; Australia (Schroeckh et al. 2003).

Petalomonas F. Stein

Petalomonas abscissa (Dujard.) F. Stein

Figs $23 \& 56$

Cyclidium abcissum Dujard.

Cells 17.5-30.5 $\mu \mathrm{m}$ long, 10.0-14.5(-21.5) $\mu \mathrm{m}$ wide, rigid, gliding euglenoid, broadly-ovoid; rounded or blunt on both ends and tapered at posterior end: with two longitudinal ribs, convex on dorsal side, flat on ventral side; flagellum as long as or slightly longer than cell.

SITE: Lampang - fish pond (KL).

General oCCURRENCE: common, fresh and marine waters; reported from Asia: China (Shi 1999); Australia (Schroeckh et al. 2003); Tasmania (Lee et al. 2005); South America: Brazil (Larsen \& Patterson 1990).

Petalomonas angusta var. pusilla (G. A. Klebs) Lemmerm.

Figs $24 \& 57$

Cells 7.5-8.5 $\mu \mathrm{m}$ long, 5.7-5.9 $\mu \mathrm{m}$ wide, ovoid; compressed, with median longitudinal groove on vertical side; anterior end narrow, slightly pointed; posterior end broadly rounded, with central part concave at ventral groove; 

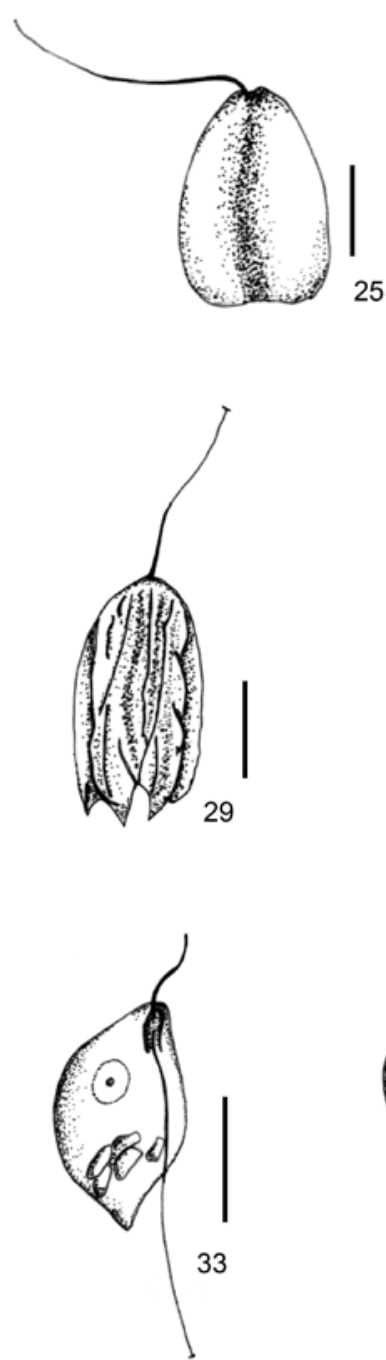
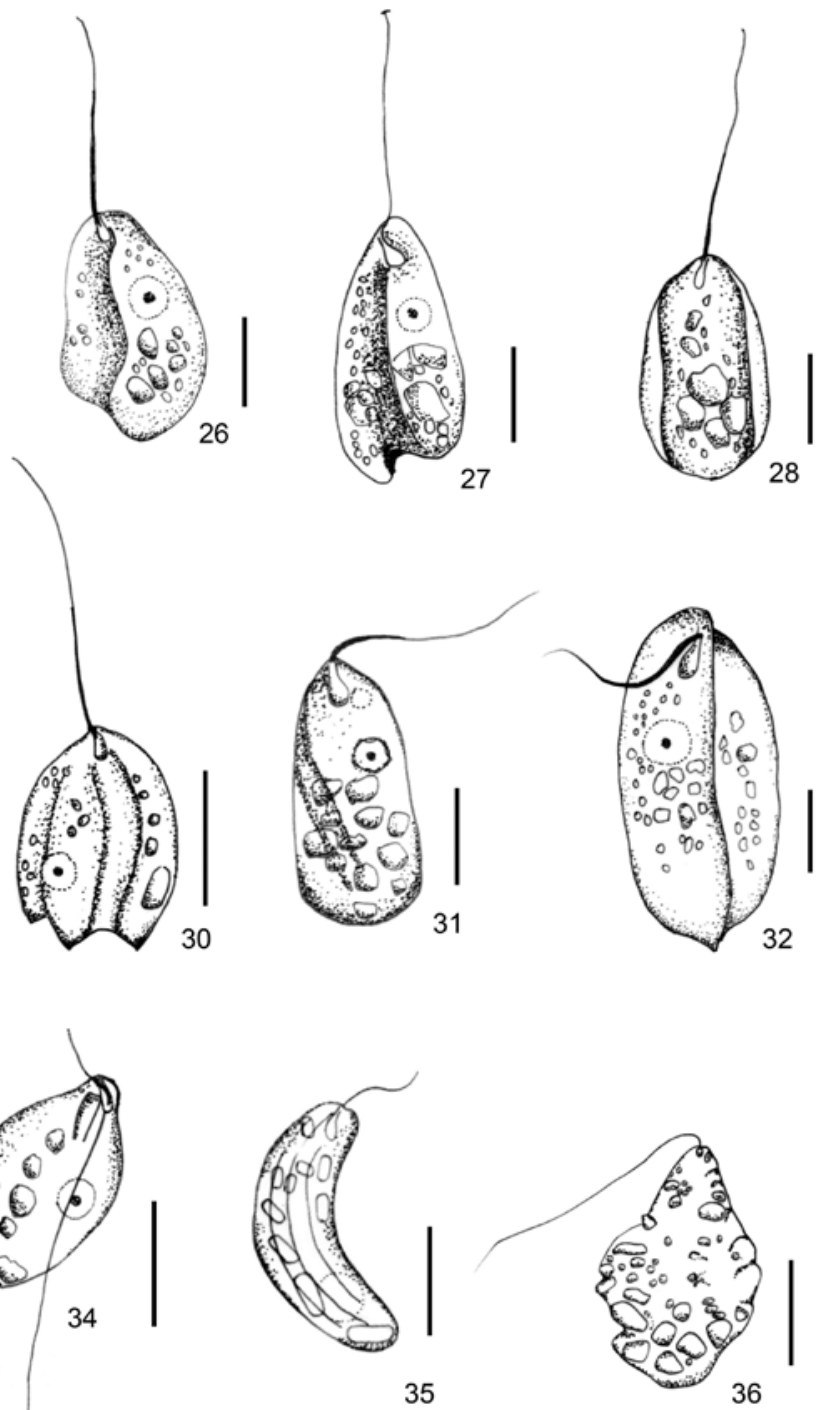

Figs 25-36. 25 - Petalomonas angusta (Klebs) Lemmerm., 26 - P. asymmetrica Schawhan \& Jahn, 27 - P. dubosqui Hollande, 28 - P. inflexa G. A. Klebs, $29-P$. irregularis Skuja, $30-P$. mira var. bicarinata Skuja, $31-P$. splendens Hollande, 32 - P. variabilis Christen, 33 \& 34 - Pleotia obliqua Schroeckh, W. J. Lee \& D. J. Patt., 35 - Rhabdomonas incurva Fresen., 36 - Urceolus pascheri Skvortzov. Scale bars $=10 \mu \mathrm{m}$.

numerous paramylon bodies, globose; flagellum as long as cell.

SiTE: Lampang - fish pond (KL).

GENERAL OCCURRENCE: common, puddles, periphyton; reported from Asia: China (Shi 1999); Europe: Germany; North America (Starmach 1983)
Petalomonas angusta (Klebs) Lemmerm.

Figs $25 \& 58$

Cells 17.5-21.3 $\mu \mathrm{m}$ long, 12.2-14.0 $\mu \mathrm{m}$ wide, ovoid; compressed, with median longitudinal groove on dorsal and ventral sides; anterior end narrow, slightly truncated; posterior end broadly 

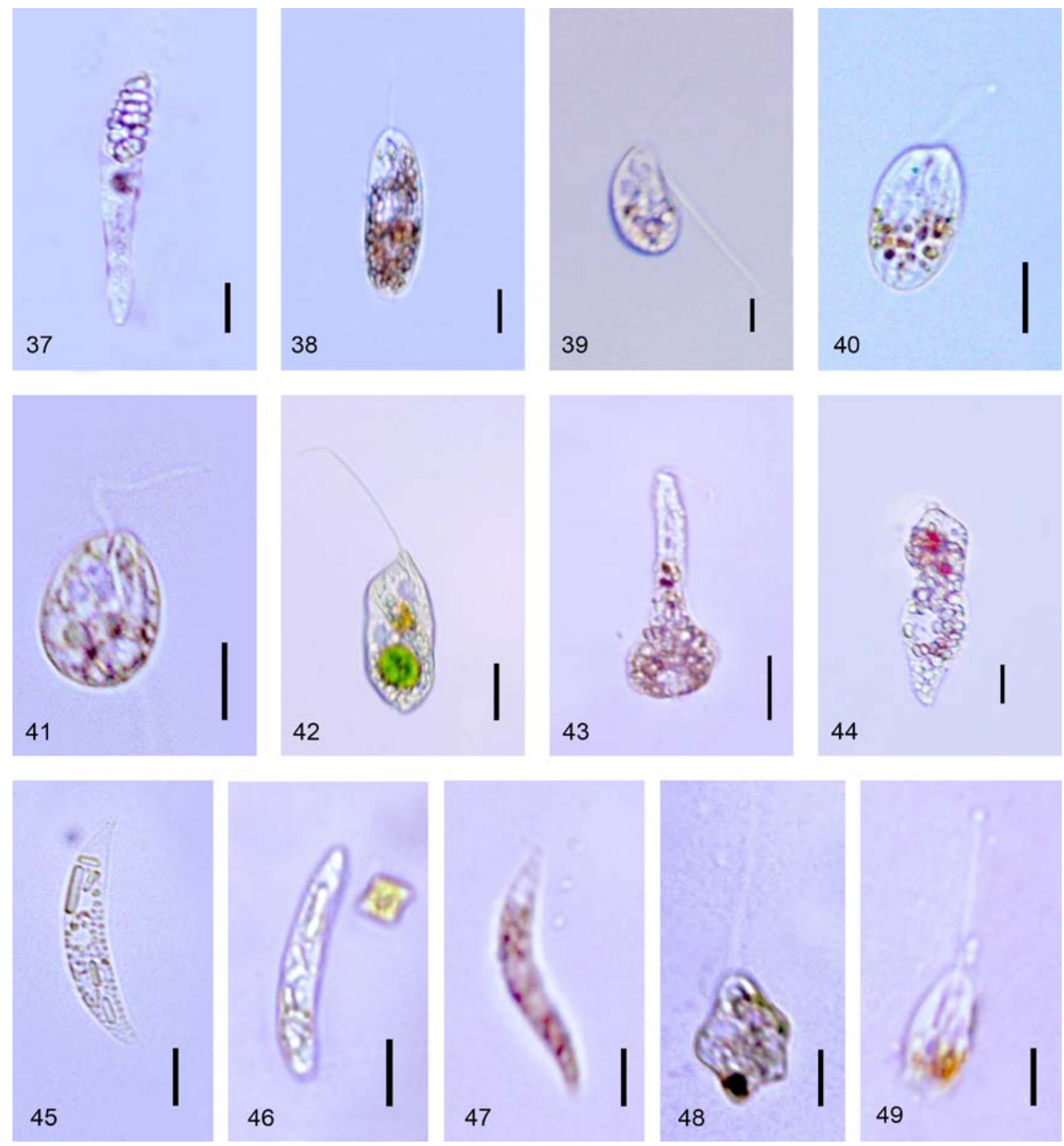

Figs 37-49. 37 - Astasia dangeardii Lemmerm., 38 - Dinema dimorphum (Skuja) Schroeckh, W. J. Lee \& D. J. Patt., 39 - D. platysomum (Skuja) W. J. Lee \& D. J. Patt., 40 \& 41-Entosiphon sulcatum (Dujard.) F. Stein, 42 - Heteronema hexagonum var. elegans Playfair, 43 \& 44 - H. polymorpha Deflandre, 45 \& 46 Menoidium pellucidum Perty, 47 - M. tortuosum (A. Stokes) Lemmerm., 48 Notosolenus pentagonus Playfair, $49-N$. mediocanellatus var. disomatus (A. Stokes) Duangjan \& Wolowski. Scale bars $=10 \mu \mathrm{m}$.

round, central part concave at ventral groove; paramylon bodies numerous, globose; flagellum as long as cell.

SITE: Lampang - fish pond (KL).
GENERAL OCCURRENCE: common, puddles, periphyton; reported from Asia: Malaysia (Yamagishi 1992, 2010), China (Shi 1999); Europe: Ukraine, Russia, Latvia, Hungary, Romania, Greece; West Africa; North America (Vetrova 1980). 
Petalomonas asymmetrica Schawhan \& Jahn

Figs $26 \& 59$

Cells 20.0-23.5 $\mu \mathrm{m}$ long, 12.5-14.5 $\mu \mathrm{m}$ wide, ovoid, flat; anterior end narrowing, pointed; posterior end broadly rounded, truncated; left side of cell with deep groove; dorsal side thicker than ventral side; granules on both sides of groove; flagellum 1.5 times longer than cell.

SITE: Lampang - fish pond (KL).

General ocCURRENCE: rare, fish pond; reported from North America: Iowa (Shawhan \& Jahn 1947).

Petalomonas dubosqui Hollande Figs $27 \& 60$

Cells 27.5-28.0 $\mu \mathrm{m}$ long, 13.5-13.7 $\mu \mathrm{m}$ wide, ovoid; pointed at anterior end; expanded and incised at posterior end; convex depending on location of cell; widely grooved on ventral side; flagellum slightly longer than cell.

Site: Lampang - fish ponds (KL).

General oCCURRENCE: not common, pond, ditches, reported from Asia: Malaysia (Yamagishi 2010); Europe: France, Netherlands (HuberPestalozzi 1955).

Petalomonas inflexa Klebs

Figs $28 \& 61$

Cells 23.5-28.5 $\mu \mathrm{m}$ long, 13.5-16.5 $\mu \mathrm{m}$ wide, flat; anterior end narrow, round; posterior end broadly rounded or recessed; flagellum almost as long as cell.

SITE: Lamphun - ditch (LL).

GENERAL OCCURRENCE: common, stagnant water bodies, ponds and lakes, $\alpha-\beta$-mezosaprobe; reported from Europe: Bulgaria, Belgium, Greece, Latvia, Poland, Russia, Ukraine (Vetrova 1980); Asia (Starmach 1983).

\section{Petalomonas irregularis Skuja Figs 29 \& 62}

Cells 22.8-28.0 $\mu \mathrm{m}$ long, 12.1-14.0 $\mu \mathrm{m}$ wide, broadly oval in outline, flat; anterior end narrow, with small cavity; posterior end extended, with 2-3 irregular lobes, often branches on ends; ventral side almost flat or weakly convex; flagellum as long as or longer than cell.

Site: Chiang Mai - garden pond (AG).
GENERAL OCCURRENCE: small forest puddles, ponds, ephemeral waters; reported from Europe: Sweden, Russia, Ukraine (Vetrova 1980).

Petalomonas mira var. bicarinata Skuja

Figs $30 \& 63$

Cells 12.5-18.7 $\mu \mathrm{m}$ long, 10-15 $\mu \mathrm{m}$ wide, broadly oval; two low ribs running the length of cell bearing two lobes at postrior end; flagellum as long as cell.

Sites: Lampang - fish pond (KL); Chiang Rai garden pond (BY1).

GENERAL OCCURRENCE: rare, ditches, lake littoral; reported from Europe: Latvia, Russia, Ukraine (Starmach 1983).

Petalomonas splendens Hollande Figs 31 \& 64

Cells 25.0-26.6 $\mu \mathrm{m}$ long, 12.5-13.3 $\mu \mathrm{m}$ wide, ovoid; anterior end with small recess; slightly widening S-shaped groove on dorsal side; flagellum almost as long as cell.

Site: Chiang Mai - fish pond (UM).

GENERAL OCCURRENCE: puddles; reported from South America: Argentina (Conforti 1981a, b; Tell 1985); Europe: France (Starmach 1983).

Petalomonas variabilis Christen Figs 32 \& 65

Cells 48.7-50.9 $\mu \mathrm{m}$ long, 22.5-24.5 $\mu \mathrm{m}$ wide, longitudinally flat, with high rib on dorsal side, sometimes wavy, almost parallel on sides; anterior end bluntly rounded; short appendix at posterior end; throat hole under top; emergent flagellum directed anteriorly, as long as cell. (MJ).

SiTES: Chiang Mai - garden pond (AG), fish pond

GENERAL OCCURRENCE: not common, ditches, swamps; reported from Europe: Switzerland, Ukraine (Starmach 1983); Asia: Malaysia (Yamagishi 2010)

Ploeotia Dujard.

Ploeotia obliqua Schroeckh, W. J. Lee

\& D. J. Patt.

Figs 33, 34, 66, 67

Cells 12.5-18.5 $\mu \mathrm{m}$ long, 7.5-11.5 $\mu \mathrm{m}$ wide, rigid, obovoid or spindle-shaped; posterior end 

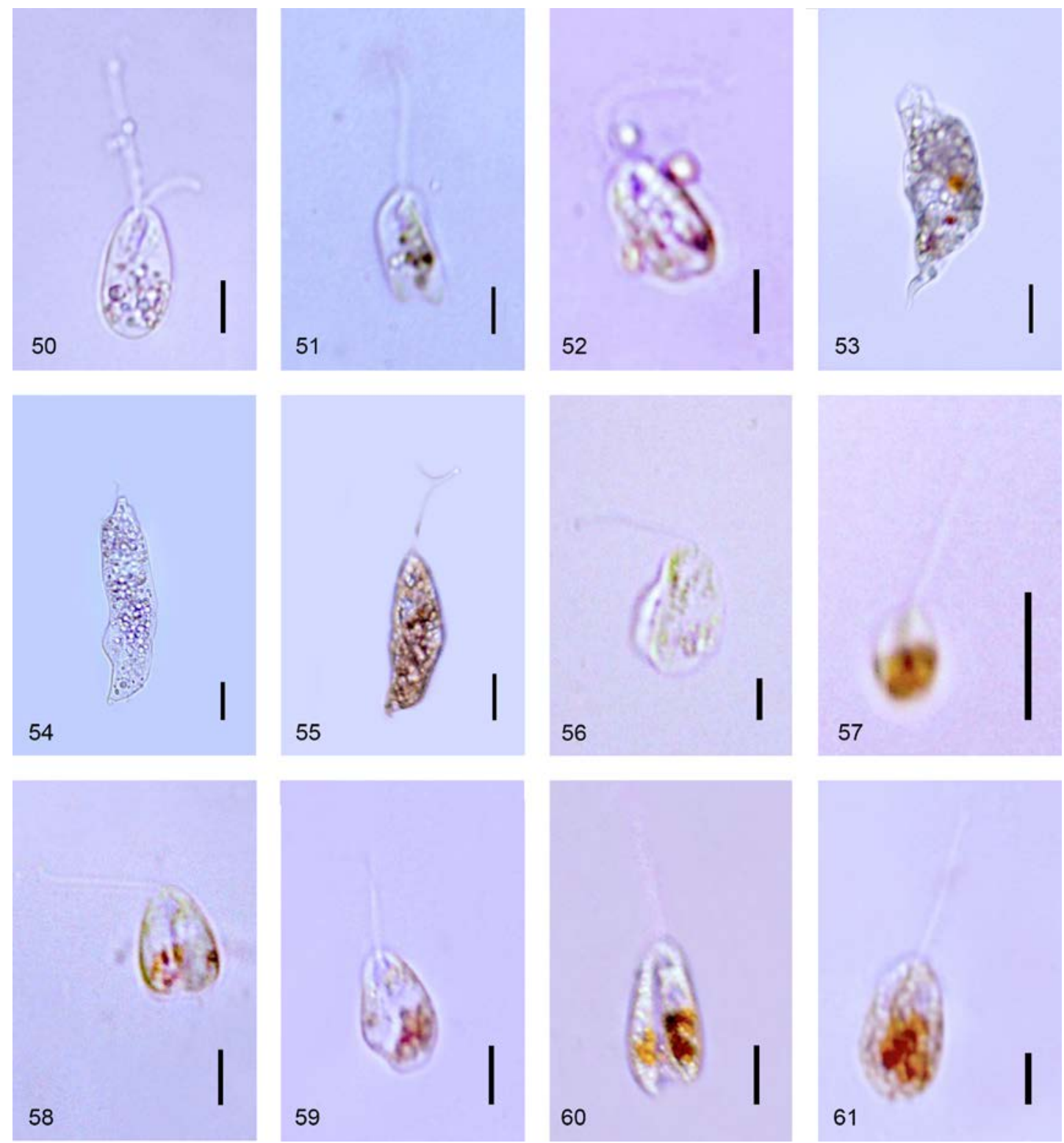

Figs 50-61. 50 - Notosolenus similis Skuja, 51 - N. steinii (G. A. Klebs) Schroeckh, W. J. Lee \& D. J. Patt., 52 - N. stenoschismus Skuja, 53 - Peranema kupfferi Skuja, 54 \& 55 - P. pleururum Skuja, 56 - Petalomonas abscissa (Dujard.) F. Stein, 57 - P. angusta var. pusilla (Klebs) Lemmerm., 58 - P. angusta (G. A. Klebs) Lemmerm. var. angusta, 59 - P. asymmetrica Schawhan \& Jahn, 60 - Petalomonas dubosqui Hollande, $61-$ P. inflexa Klebs. Scale bars $=10 \mu \mathrm{m}$.

gradually tapered, more or less convex on one side; siphon inside of cell, its front edge situated above opening of throat; anterior flagellum as long as cell, posterior flagellum twice the length of cell.
SiTES: Chiang Rai - fish pond (CC1), Lampang fish pond (KL).

GENERAL OCCURRENCE: common, stagnant water bodies, fish ponds, saprophytic (Vetrova 1980); reported from Asia: China (Shi 1999); 

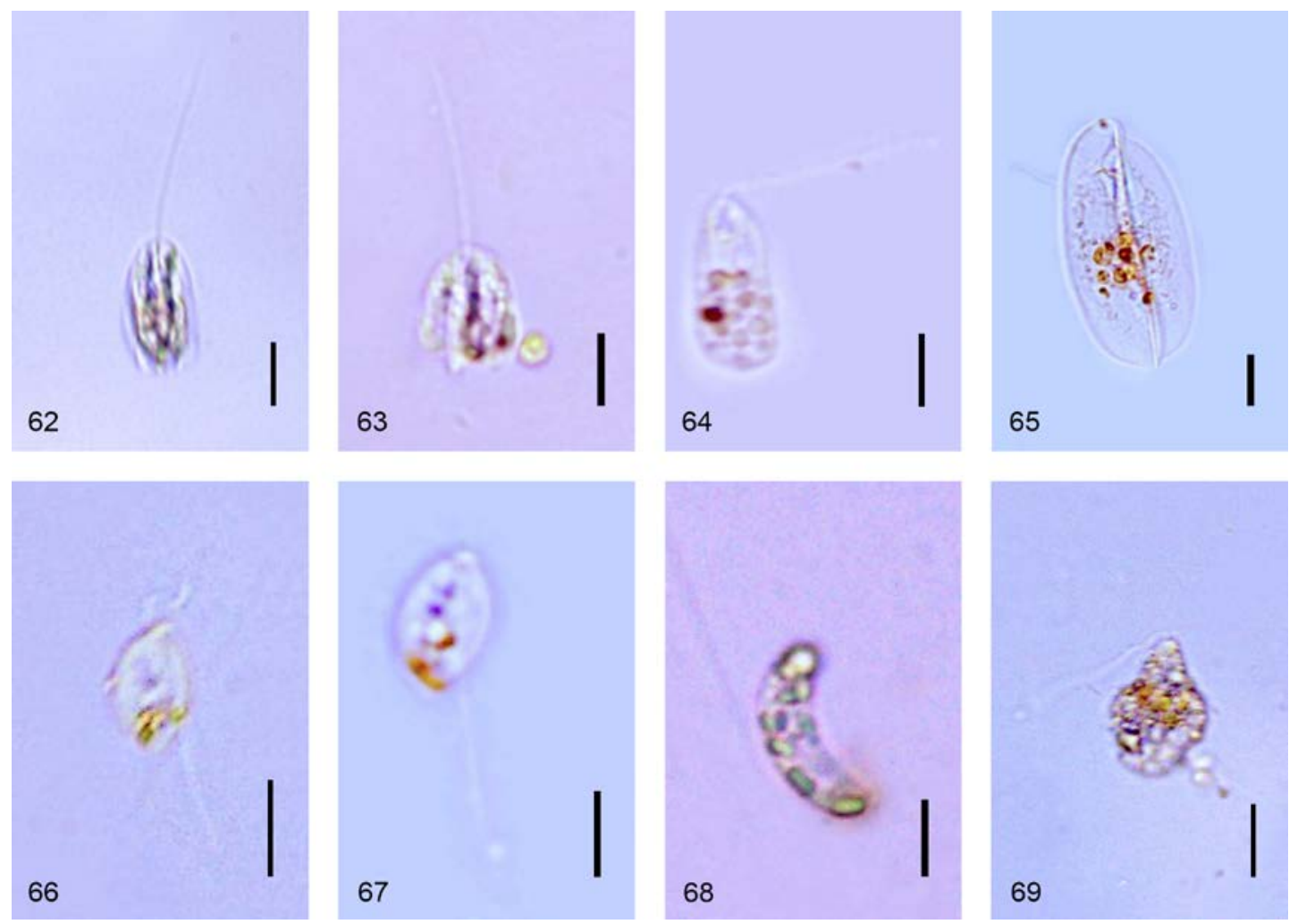

Figs 62-69. 62 - Petalomonas irregularis Skuja, 63 - P. mira var. bicarinata Skuja, 64 - P. splendens Hollande, 65 - P. variabilis Christen, 66 \& 67 - Pleotia obliqua Schroeckh, W. J. Lee \& D. J. Patt., 68 - Rhabdomonas incurva Fresen., 69 - Urceolus pascheri Skvortzov. Scale bars $=10 \mu \mathrm{m}$.

Europe: Russia, Ukraine, Latvia, Sweden, Hungary (Vetrova 1980).

\section{Rhabdomonas Fresen.}

\section{Rhabdomonas incurva Fresen.}

Figs $35 \& 68$

Menoidium incurvum Fresen.

Cells 12.5-23.5 $\mu \mathrm{m}$ long, 5-7 $\mu \mathrm{m}$ wide, rigid, shortly cylindrical; slightly bent, with round ends; pellicle with six steeply helical longitudinal striations; flagellum $c a 1 / 2$ cell length.

Sites: Chiang Mai - fish pond (MJ1), Lampang fish pond (KL); Lamphun - ditch (LL).

GENERAL OCCURRENCE: very common, ephemeral water bodies, sphagnum pools, planktonic; Asia, Europe, Australia (Wołowski 2011); North America: USA (Bittencourt-Oliveira 1997; Wołowski \& Walne 1997); South America: Argen- tina (Tell 1985), Brasilia (Alves-da-Silva \& Menezes 2010).

\section{Urceolus Mereschk.}

Urceolus pascheri Skvortzov

Figs $36 \& 69$

Cells 17.6-20.0 $\mu \mathrm{m}$ long, 7.5-14.0 $\mu \mathrm{m}$ wide, ovoid; anterior end gradually narrowing, oblique; posterior end wide and bluntly rounded; pellicle slimy, covered with detritus particles; flagellum as long as or slightly longer than cell.

Note. We did not see striations due to the density of detritus on the pellicle.

SiTE: Lampang - fish pond (KL).

GENERAL OCCURRENCE: not common, slowly flowing waters with pH 6.7 (Vetrova 1980), littoral, mud, benthos; reported from Asia: northern China (Shi 1999); Europe: Ukraine, Russia (Vetrova 1980). 


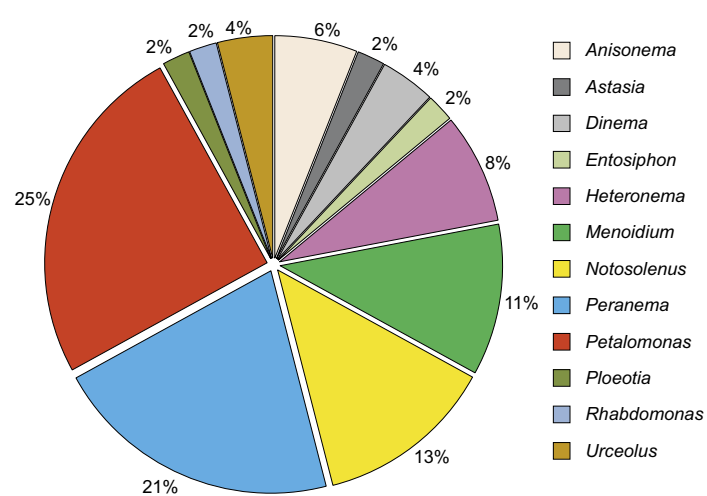

Fig. 70. Percentage of heterotrophic euglenoids at all sampling sites.

Earlier data on the colorless euglenoids occurring in Thailand were reported mainly as occurring worldwide by a group of zoologists. Among 171 protozoan taxa occurring in Bung Borapet, Nakhon Sawan Province, Jaisa-ard (2000) recognized only 5 taxa: Astasia klebsii Lemmerm., Urceolus sabulosus A. Stokes, Entosiphon sulcatum (Dujard.) F. Stein, Heteronema acus (Ehrenb.) F. Stein and Peranema trichophorum (Ehrenb.) F. Stein. During work on protozoan organisms from 1982 to 1999, Charubhun and Charubhun (2000) reported some heterotrophic euglenoids, such as Astasia klebsii Lemmerm., Menoidium falcatum Zacharias, Peranema trichophorum (Ehrenb.) F. Stein, Heteronema acus (Ehrenb.) F. Stein, Entosiphon sulcatum (Dujard.) F. Stein and Anisonema truncatum F. Stein. Matchacheep and Dumrongrojwattana (2010) reported Heteronema acus (Ehrenb.) F. Stein, Peranema trichophorum (Ehrenb.) F. Stein and Entosiphon sulcatum (Dujard.) F. Stein. Recently, Chaimongkhon (2016) reported 14 taxa belonging to 6 genera of heterotrophic euglenoids in some waters of Thailand: Anisonema (4 taxa), Heteronema (1 taxon), Menoidium (1 taxon), Notosolenus (2 taxa), Peranema (4 taxa) and Petalomonas (2 taxa).

This study adds 30 colorless euglenoid taxa to the list of heterotrophic euglenoids of Thailand (Table 3). Among the new taxa, representatives of Petalomonas and Peranema were abundant (Fig. 70). Most of the reported taxa always occurred in the sediment of highly humic waters.
Our work confirms statements made in other publications that heterotrophic euglenoids occur in waters polluted by autochthonous organic matter (Vetrova 1980; Wołowski 1991, 1998). Often they occur in waters with high content of dissolved iron, ammonia and nitrates. Several taxa are found in oligotrophic and slightly mineralized water, and also in brackish and marine water. They have also been observed in coastal waters of stagnant waterbodies. Since heterotrophic euglenoids occupy different niches in different climate zones, we suggest that they should be treated as ubiquitous and that they are of very limited value as indicators of water pollution or climate changes. Knowledge of the taxonomy and biogeography of heterotrophic euglenoids is still poor. We need more environmental studies of this group, which is an important link in the evolutionary development of Euglenophyta.

ACKNOWLEDGEMENTS. We thank our many colleagues for their assistance, and the Applied Algal Research Laboratory, Department of Biology, Faculty of Science, Chiang Mai University, Thailand, for making its data base available and for providing access to equipment. We are especially grateful to Professor Won Je Lee for very helpful remarks and suggestions on an earlier version of the manuscript, Dr. Jan J. Wójcicki for very useful discussions, the anonymous reviewers for their critical comments, and Dr. Thomas Dempster for attention to the language of an earlier version. This study was supported by the Royal Golden Jubilee Ph.D. Program of Thailand and by statutory funds of the W. Szafer Institute of Botany, Polish Academy of Sciences.

\section{REFERENCES}

Alves-DA-Silva S.M. \& Friedrich F. 2009. Novos e raros registros de Euglenophyta incolores na Planície Costeira do Rio Grande do Sul, Brasil. Acta Bot. Brasil. 23(4): 1076-1083.

Alves-DA-Silva S. M. \& Menezes M. 2010. Euglenophyceae. In: R. C. Forzza, J. F. A. Baumgratz, C. E. M. Bicudo, A. A. Carvalho Jr., A. Costa, D. P. Costa, M. Hopkins, P. M. Leitman, L. G. Lohmann, L. Costa Maia, G. Martinelli, M. Menezes, M. P. Morim, M. A. N. Coelho, A. L. Peixoto, J. R. Pirani, J. Prado, L. P. Queiroz, V. C. Souza, J. R. Stehmann, L. S. Sylvestre, B. M. T. WALTER \& D. ZAPPI, Catalogo de plantas e fungos do Brasil. 1: 383-404. Jardim Botânico do Rio de Janeiro, Rio de Janeiro. 
Alfinito S. 2011. A check list of the freshwater algal flora of Sierra Leone, Tropical West Africa. I. Cyanophyceae to Conjugatophyceae (exclusive of Bacillariophyceae). Biodiversity Journal 2(3): 121-144.

Angeler D. G. 1999a. Distigma proteus var. longicauda var. nov. - a new colourless euglenoids described from cultures. Algol. Stud. 92: 19-33.

Angeler D. G. 1999b. Zur systematischen Stellung von Astasia tortuosa (Stokes) Popova, inkl. A. tortuosa var. harrisii (A.G. Prongsheim) Angelerstat. Nov. (Euglenophyta). Phyton (Horn) 39(1): 27-35.

Angeler D. G. 2000. Taxonomy and morphology of Distigmna elegans and Khawkinea fritschii, rare euglenoids rediscovered in the Iberian Peninsula. Nova Hedwigia 70(3-4): $397-408$.

Angeler D. G., Schagerl M. \& Müllner A. N. 2002. Taxonomic comments on the genus Menoidium (Euglenozoa), with a description of Menoidium intermedium sp. nov. European Journal of Protistology 38: 393-404.

AsAul Z. I. 1975. Survey of the euglenophytes of the Ukrainian SSR. Naukova Dumka, Kiev (in Ukrainian).

Bicudo C. E. M. \& Bicudo D. C. 1987. Some new and rare Euglenophyceae from the state of Săo Paulo, southern Brazil. Acta Bot. Brasil. 1: 43-48.

Bittencourt-Oliveira M. C. 1997. Fitoplâncton do rio Tibagi, estado do Paraná, Brasil.: Nostocophyceae, Chlorophyceae, Euglenophyceae, Chrysophyceae, e Tribophyceae. Hoehnea 24: 1-20.

Cabala J. 2003. Some interesting colourless euglenophytes found in southern Poland. Acta Soc. Bot. Poloniae 72: 241-247.

Chaimongkhon P. 2016. Biodiversity and molecular identification using ISSR markers of Euglenoids in some water resources of Thailand. Ph.D. Thesis, Department of Biology, Faculty of Science, Chiang Mai University, Chiang Mai.

Charubhun B. \& Charubhun N. 2000. Biodiversity of freshwater Protozoa in Thailand. Kasetsart J. 34: 486-494.

Christen H. R. 1959. New colorless Eugleninae. J. Protozool 6: $292-303$.

Christen H. R. 1962. Zur Taxonomie der farblosen Eugleninen. Nova Hedwigia 4(3-4): 437-464.

Conforti V. 1979. Contribución al conocimiento de las algas de agua dulce de la provincia de Buenos Aires (Argentina). V. Physis, B 38(95): 11-19.

CONFORTI V. 1980. Contribución al conocimiento de las algas de agua dulce de la provincia de Buenos Aires (Argentina). VI. Physis, B 39(96): 1-8.

Conforti V. 1981a. Contribución al conocimiento de las algas de agua dulce de la provincia de Buenos Aires (Argentina). VII. Physis, B 39(97): 47-51.
CONFORTI V. 1981b. Contribución al conocimiento de las algas de agua dulce de la provincia de Buenos Aires (Argentina). VIII. Lilloa 35(3): 95-102.

CONFORTI V. 1986. Contribución al conocimiento de las algas de agua dulce de la provincia de Buenos Aires (Argentina). XI. Physis, B 44(106): 13-18.

Cunha A. M. 1913. Contribuiçăo para o conhecimento da fauna de protozoarios do Brazil. Mém. Inst. Oswaldo Cruz 5(2): $101-122 \& 522-524$.

Deflandre G. 1932. Contributions à la connaissance des Flagellées libres. Annales de Protistologie 3: 219-239.

DuangJan K. \& Wolowski K. 2013. New taxa of loricate euglenoids Strombomonas and Trachelomonas from Thailand. Polish Bot. J. 58(1): 337-345.

Duanguan K., Wolowski K. \& Peerapornpisal Y. 2014. New records of the Phacus and Monomorphina (Euglenophyta) taxa for Thailand. Polish Bot. J. 59(2): 235-247.

DUJARDIN F. 1841. Histoire naturelle des Zoophytes: Infusoires. Librairie Encyclopédique de Roret, Paris.

Eaton A. D., Clesceri L. S., Rice E. W., Greenberg A. E. \& Franson M. A. H. 2005. Standard Methods for the Examination of Water and Wastewater. $21^{\text {st }}$ ed. American Public Health Association (APHA), Washington.

Ehrenberg C. G. 1831. Animalia evertebrata. In: P. C. HemPRICH \& C. G. Ehrenberg (eds), Symbolae physicae. Pars zoologica. G. Reimeri, Berolini.

Figueroa-Torres M. G., Arana-Magallón F., Almanza-EnCARnación S., Ferrara-Guerrero M. J. \& Ramos-EsPINosa M. G. 2015. Microalgas del Área Natural Protegida Ejidos de Xochimilco y San Gregorio Atlapulco, México. CienciaUAT 9(2): 15-29.

Fresenius G. 1858. Beiträge zur Kenntniss mikroskopischer Organismen. Abh. Senckenberg. Naturf. Ges. 2: 211-242.

Guiry M. D. \& Guiry G. M. 2016. AlgaeBase. World-wide electronic publication, National University of Ireland, Galway. [20 August 2016]. http://www.algaebase.org.

Gupta R. K. 2012. Algae of India. 2. A checklist of Chlorophyceae, Xanthophyceae. Chrysophyceae and Euglenophyceae. Botanical Survey of India, Ministry of Environment $\&$ Forests. India, Salt Lake \& Kolkata.

Hansgirg A. 1886. Prodromus der Alpenflora von Böhmen. 1. Die Rhodophyceen, Pheophyceen und einen Teil der Chlorophyceen. Fr. Řivnáč, Prague.

Huber-Pestalozzi G. 1955. Das Phytoplankton des Süßwassers Systematik und Biologie. E. Schweizerbart'sche Verlagsbuchhandlung, Stuttgart.

JAHN T. L. \& JAHN F. F. 1949. How to know the Protozoa. W. C. Brown Company Publishers, Dubuque, Iowa.

JAHN T. L. \& McKibBEN W. R. 1937. A colourless euglenoid flagellate Khawkinea halli n.g. n.sp. Trans. Amer. Microscop. Soc. 56. 48-54. 
JAISA-ARD P. 2000. Biodiversity of Protozoa at community area in Bung Borapet Nakhon Sawan Province. Science and Technology, Rajabhat Nakhon Sawan University, Nakhon Sawan.

KLEBS G. A. 1892. Flagellatenstudien. Theil II. Z. Wiss. Zool. 55: $352-445$.

Kudo R. R. 1977. Protozoology. 5 ed. Charles C. Thomas Publisher, Illinois.

Kusel-Fetzmann E. 2002. Die Euglenophytenflora des Neusiedler Sees (Burgenland, Österreich). Abh. Zool.-Bot. Ges. Österreich 32: 1-102.

Larsen J. \& Patterson D. J. 1990. Some flagellates (Protista) from tropical marine sediments. J. Nat. Hist. 24: 801-937.

LEE W. J. 2002. Some free-living heterotrophic flagellates from marine sediments of Inchon and Ganghwa Island, Korea. Korean J. Biol. Sci. 6: 125-143.

Lee W. J., Blackmore R. \& Patterson D. J. 1999. Australian records of two lesser known genera of heterotrophic euglenoids - Chasmostoma Massart, 1920 and Jenningsia Schaeffer, 1918. Protistology 1: 10-16.

Lee J. J., Leedale G. F. \& Bradbury P. (eds) 2000. An Illustrated Guide to the Protozoa. 2. Society of Protozoologists/ Allen Press, Lawrence, Kansas, U.S.A.

Lee W. J., Brandt S. M., V̌rrs N. \& Patterson D. J. 2003. Darwin's heterotrophic flagellates. Ophelia 57: 63-98.

Lee W. J, Simpson A. G. B. \& Patterson D. J. 2005. Free-living heterotrophic flagellates from freshwater sites in Tasmania Australia, a Field Survey. Acta Protozologica 44: 321-350.

LeEdale G. F. 1967. Euglenoid flagellates. Prentice-Hall, Inc., New Jersey.

Leedale G. F. 1985. Order 3. Euglenida Butschli, 1884. In: J. J. Lee, S. H. Hutner \& E. C. Bovee (eds), An illustrated guide to Protozoa, pp. 41-53. Society of Protozoologists/Allen Press, Lawrence, Kansas, U.S.A.

Leedale G. F. 2000. Class Euglenoidea Bütschli, 1884, order Euglenida Bütschli, 1884. In: J. J. LeE, G. F. LeEdALE \& P. Bradbury (eds), An Illustrated Guide to the Protozoa, 2: 1136-1157. Society of Protozoologists/Allen Press, Lawrence, Kansas, U.S.A.

Lemmermann E. 1913. Eugleninae. In: A. Pascher (ed.), Die Süsswasser-Flora Deutschlands, Österreichs und der Schweiz. 2. Flagellatae 2: 115-174. Gustav Fischer, Jena.

Matchacheep S. \& Dumrongrojwattana P. 2010. Freshwater protozoa of Chonburi province, eastern Thailand (Protozoa: Mastigophora, Sarcodina and Ciliophora). In: Proceedings of $45^{\text {th }}$ Kasetsart University Annual Conference: Science, pp. 65-571. Bangkok.

Menezes M. 1993. New records of heterotrofic flagellates (Euglenophyta) from Brasil. Nova Hedwigia 56(1-2): 131-137.

MereschKowsky K. S. 1879. Studien über Protozoen des nordlichen Russlands. Archiv für Mikroskopische Anatomie 16: $153-248$.
Patterson D. J. \& Lee W. J. 2000. Geographic distribution and diversity of free-living heterotrophic flagellates. In: B. S. C. Leadbeater \& J. C. Green (eds), The Flagellates. Unity, diversity and evolution, pp. 269-287. Taylor $\&$ Francis, London and New York.

PERTY M. 1852. Zur Kenntniss kleinster Lebensformen: nach Bau, Funktionen, Systematik, mit Specialverzeichniss der in der Schweiz beobachteten, pp. 1-228. Verlag von Jent \& Reinert, Bern

Piatek J. 2007. Algae of the peat bog in Modlniczka near Kraków (Wyżyna Krakowsko-Częstochowska upland, S Poland). Polish Bot. Stud. 24: 1-74.

Playfair G. I. 1921. Australian freshwater flagellates. Proc. Linn. Soc. New South Wales 56: 1-146.

Poniewozik M. 2005. Some Heteronema species (Euglenophyta) occurring in Łęczna-Włodawa Lakeland (Eastern Poland). Acta Soc. Bot. Poloniae 74(4): 323-327.

Poniewozik M. 2012. Colourless euglenophytes - new and rare species for Polish flora. Fragm. Florist. Geobot., Ser. Pol. 19(1): 161-176 (in Polish with English summary).

PoniewoziK M. 2014. The euglenoids genera Astasia and Menoidium (Euglenozooa) from eastern Poland. Nova Hedvigia 99 (1-2): 193-212.

Popova T. G. \& SAfonova T. A. 1976. Flora plantarum cryptogamarum URSS. 9. Euglenophyta. Izdatel'stvo Nauka, Leningrad (in Russian).

Pringsheim E. G. 1942. Contribution to our knowledge of saprophytic algae and Flagellata III. Astasia, Distigma, Menoidium and Rhabdomonas. New Phytol. 41: 171-205.

Pringsheim E. G. 1963. Farblose Algen. Ein Beitrag zur Evolutionsforschung. Fischer, Stuttgart.

Reinhold T. 1937. La flore fossile ŕ diatomées de Moliro (Lac Tanganyika Katanga). Ann. Soc. Géol. Belgique 61(1): 39-47.

Rosa Z. M., Ungaretti I., Kremer L. M., Alves-Da-Silva S. M., Calegaro V. L. M. \& Werner V. R. 1987. Ficoflora de ambientes lenticos - estudo preliminar da regiao de Charqueadas, Rio Grande do Sul, Brasil, com vistas a avaliacao ambiental. Acta Bot. Brasil. 1(2): 165-188.

Schroeckh S., Lee W. J. \& Patterson D. J. 2003. Free-living heterotrophic flagellates from freshwater sites in mainland Australia. Hydrobiologia 494: 131-166.

SHAwhAN F. M. \& JAHN T. L. 1947. A survey of the genus Petalomonas Stein (Protozoa: Euglenida). Trans. Amer. Microscop. Soc. 66: 182-189.

SHI Z. 1999. Flora alarum sinicarum aquae dulcis. 6. Euglenophyta. Science Press, China.

SILVA P. C. 1960. Remarks on algae nomenclature. III. Taxon 9(1): 18-25.

Skuja H. 1931. Die Algenflora der Insel Moritzholm im Usmaitensee. Arbeiten Naturf. Vereins Riga 19: 1-20. 
Skuja H. 1934. Beitrag zur Algenflora Lettlands I. Acta Horti Bot. Univ. Latv. 7: 25-85.

Skuja H. 1939. Beitrag zur Algenflora Lettlands II. Acta Horti Bot. Univ. Latv. 11/12: 41-169.

SKuJA H. 1964. Grundzüge der Algenflora und Algenvegetation der Fjeldgeogenden u, Abisco in Swedisch-Lappland. Nova Acta Regiae Soc. Sci. Upsal., Ser. 4 18(3): 1-465.

Sмiтн T. E. 2010. Revised list of algae from Arkansas, U.S.A. and new additions. Int. J. Algae 12(3): 230-256.

Starmach K. 1983. Flora Slodkowodna Polski (Euglenophyta). 3. Państwowe Wydawnictwo Naukowe, Kraków.

SteIn F. R. 1878. Der Organismus der Infusionsthiere nach eigenen Forschungen in systematischere Reihenfolge bearbeitet. III. Abtheilung. Die Naturgeschichte der Flagellaten oder Geisselinfusorien. I. Hälfte, Den noch nicht abgeschlossenen allgemeinen Teil nebst Erklärung: Der sämtlichen Abbildungen enthaltend. Verlag von Wilhelm Engelmann, Leipzig.

Stokes A. C. 1884. A preliminary contribution toward a history of the fresh-water infusoria of the United States. J. Trenton Nat. Hist. Soc. 1: 72-319.

Tell G. 1985. Catálogo de las algas de agua dulce de la República Argentina. Biblioth. Phycol. 70: i-vi + 1-283.

Vetrova Z. I. 1980. Bescvetnye vodorosli Ukrainy. Izdattel'stvo Naukova Dumka, Kiev (in Russian).

Vetrova Z. I. 2004. Flora algarum aquariorum continentalium Ucrainicae. Euglenophyta. 2. Nacionalnaya Akademia Nauk Ukrainy, Kiev (in Russian).
Whitford L. A. 1956. Additions to the Fresh-Water Algae in North Carolina I. Trans. Amer. Microscop. Soc. 75(2): 196-203.

Whitford L. A. 1958. Phytoplankton in North Carolina lakes and ponds. J. Elisha Mitchell Sci. Soc. 74: 143-157.

WhiTFORD L. 1979. Additions to the freshwater algae in North Carolina, part 9. J. Elisha Mitchell Sci. Soc. 95: 42-47.

Wolowski K. 1991. New and rare species of the colourless Euglenophyta in Poland. Fragm. Florist. Geobot. 36(1): 105-115.

Wolowski K. 1998. Taxonomic and Environmental study on euglenophytes of the Krakow - Czestochowa upland (southern Poland). Fragm. Florist. Geobot., Suppl. 6: 1-192.

Wolowski K. 2011. Phylum Euglenophyta. In: D. M. John, B. A. Whitton \& A. Brook (eds), The freshwater Algal Flora of the British Isles, $2^{\text {nd }}$ ed., pp: 181-239. Cambridge University Press, Cambridge.

Wolowski K. \& Walne P. L. 1997. Euglenophytes from the Southeastern United States I. Colorless species. Algol. Stud. 86: 109-135.

Wolowski K., Duanguan K. \& Peerapornpisal Y. 2015. Colacium minimum (Euglenophyta), a new epiphytic species for Asia. Polish Bot. J. 60(2): 179-185.

Yamagishi T. 1992. Plankton Algae in Taiwan (Formosa). Uchida Rokakuho, Tokyo.

Yamagishi T. 2010. Plankton Algae of Southeast Asia. Bishen Singh Mahendra Pal Singh, India. 